Check for updates

Cite this: RSC Adv., 2017, 7, 34182

\title{
The removal of heavy metal ions from aqueous solutions by amine functionalized cellulose pretreated with microwave $-\mathrm{H}_{2} \mathrm{O}_{2}$
}

\author{
Cunzhi Zhang, (DD ab Jingjing Su, ${ }^{\text {ab }}$ Hongxiang Zhu, ${ }^{\text {ab }}$ Jianhua Xiong, ${ }^{\text {cd }}$ Xinliang Liu, ${ }^{\text {ab }}$ \\ Dongxue Li, ${ }^{\mathrm{ab}}$ Yangmei Chen ${ }^{\mathrm{ab}}$ and Yunhua $\mathrm{Li}^{\mathrm{ab}}$
}

\begin{abstract}
A new biosorbent (PEI/SA-MCC $\mathrm{MV}_{\mathrm{MV}}$ ) with abundant amino and carboxyl groups was prepared by grafting polyethylenimine (PEI) onto carboxylated microcrystalline cellulose $\left(S A-M C C_{M V}\right.$ ), which was obtained through grafting succinic anhydride (SA) on pretreated microcrystalline cellulose $\left(\mathrm{MCC}_{\mathrm{MV}}\right)$ with microwave- $\mathrm{H}_{2} \mathrm{O}_{2}$. It was confirmed by Fourier transform infrared spectroscopy (FT-IR), scanning electron microscopy (SEM), X-ray photoelectron microscopy (XPS) and thermogravimetric (TG) that the amino and carboxyl groups were introduced onto the microcrystalline cellulose, and the amino and carboxyl groups content were $2.61 \mathrm{mmol} \mathrm{g}^{-1}$ and $4.64 \mathrm{mmol} \mathrm{g}^{-1}$, respectively. The effects of the contact time and $\mathrm{pH}$ on heavy metal ion uptake were investigated. The adsorption kinetic data was described well with the pseudo-second-order model $\left(R^{2}>0.99\right)$ and the adsorption isotherms were well fitted by the Freundlich isotherm model, demonstrating that chemisorption was the rate-controlling factor for heavy metal ion adsorption on the PEI/SA-MCC ${ }_{M V}$ biosorbent. Furthermore, the remarkable adsorption capacity (217.3 and $357.1 \mathrm{mg} \mathrm{g}^{-1}$ for $\mathrm{Cd}(॥)$ and $\mathrm{Pb}(॥)$, respectively) obtained from the Langmuir isotherm indicated that this biomass adsorbent has a promising application in water treatment.
\end{abstract}

Received 15th March 2017

Accepted 16th May 2017

DOI: $10.1039 / \mathrm{c} 7 \mathrm{ra03056h}$

rsc.li/rsc-advances properties, chemical modification is necessary. ${ }^{3}$ The complexity of the cellulose morphology and aggregated structure leads to its low reactivity and poor uniformity in chemical reactions. Therefore it is critical to improve the availability and accessibility of cellulose to reagents. A reduction in the crystallinity of cellulose via various methods would be a good way. Hydrogen peroxide $\left(\mathrm{H}_{2} \mathrm{O}_{2}\right)$ is a green and chemical oxidant. Water and oxygen as the oxidant products of $\mathrm{H}_{2} \mathrm{O}_{2}$ result in minimal environmental damage., ${ }^{4,5}$ Hydrogen peroxide $\left(\mathrm{H}_{2} \mathrm{O}_{2}\right)$ can produce the hydroxyl radical ${ }^{\circ} \mathrm{OH}$, which has a strong oxidizing potential. This can effectively break the long chains and the crystalline structure of cellulose. Compared with traditional heat-treatment, microwave (MV) pretreatment has the merits of rapid heating and minimal energy loss. ${ }^{6,7}$ Microwave irradiation with $\mathrm{H}_{2} \mathrm{O}_{2}\left(\mathrm{MV}-\mathrm{H}_{2} \mathrm{O}_{2}\right)$ is characteristically well-distributed, and an efficient and highly penetrable pretreatment method. According to the literature, this method is recommended for the hydrolysis of cellulose ${ }^{8}$ and the pretreatment of cotton fabrics. ${ }^{9}$ However, microwave irradiation (with $\mathrm{H}_{2} \mathrm{O}_{2}$ ) as a pretreatment of cellulose to obtain a modified material has not been fully investigated.

The abundant hydroxyl groups on the surface of microcrystalline cellulose allow the introduction of several heavy metal adsorption groups onto the cellulose structure. ${ }^{10}$ The modification of cellulose hydroxyl groups includes esterification, etherification and graft co-polymerization. Polyamine materials, with various adsorption functional groups, have strong 
chelation properties towards metal ions. Currently, succinic anhydride esterification and graft co-polymerization with amine substances have been reported. ${ }^{3,11}$ However, the modification of cellulose with succinic anhydride and polyethylenimine has not been reported to date.

In this study, pretreated microcrystalline cellulose $\left(\mathrm{MCC}_{\mathrm{MV}}\right)$ with microwave- $\mathrm{H}_{2} \mathrm{O}_{2}$ was modified using succinic anhydride (SA) in $N, N$-dimethylformamide (DMF) solution to obtain carboxylated microcrystalline cellulose $\left(\mathrm{SA}_{\mathrm{MCC}} \mathrm{MV}_{\mathrm{MV}}\right)$ and the

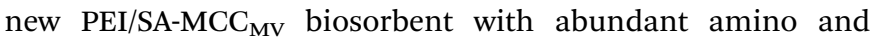
carboxyl groups was prepared by grafting PEI onto SA-MCC $\mathrm{MV}_{\text {. }}$ The adsorption ability and adsorption efficiency of PEI/SA$\mathrm{MCC}_{\mathrm{MV}}$ were increased due to the introduction of carboxyl and amino functional groups. This study may be useful for further research in the production of advanced biosorbents from cellulose.

\section{Materials and methods}

\section{Materials}

Microcrystalline cellulose (25 $\mu \mathrm{m}, \mathrm{AR})$, succinic anhydride (99\%, AR) and polyethylenimine $\left(M_{\mathrm{w}}=600,99 \%\right.$, AR) were purchased from Aladdin Corporation of China. $\mathrm{CdCl}_{2}(\mathrm{AR})$ and $\mathrm{Pb}\left(\mathrm{NO}_{3}\right)_{2}(\mathrm{AR})$ were provided by Tianjin Bodi Chemical Reagent Co., Ltd., China. Solutions of $\mathrm{Cd}(\mathrm{II})$ and $\mathrm{Pb}$ (II) were prepared by dissolving weighed amounts of the abovementioned chemicals in deionized water. $N, N$-Dimethylformamide (AR), glutaraldehyde (AR) and hydrogen peroxide (AR) used in the synthesis process were obtained from Chengdu Kelon chemical reagent factory, China. $\mathrm{NaOH}$ solution $\left(0.1\right.$ and $\left.0.01 \mathrm{~mol} \mathrm{~L}^{-1}\right)$ and $\mathrm{HNO}_{3}$ solution ( 0.1 and $\left.0.01 \mathrm{~mol} \mathrm{~L}^{-1}\right)$ were prepared using sodium hydroxide (AR) and nitric acid (AR) to adjust the $\mathrm{pH}$ of aqueous media. All reagents were analytical reagent grade.

\section{Synthesis of PEI/SA-MCC ${ }_{\text {MV }}$}

At full power, the microwave reactor delivered approximately $1800 \mathrm{~W}$ of microwave energy at a frequency of $2450 \mathrm{MHz}$ and was controlled by a microcomputer that monitored the operation. ${ }^{12}$ Pre-processing was performed in a digestion tank with $\mathrm{H}_{2} \mathrm{O}_{2}$ solution (9\%) and MCC (solid-liquid ratio $1: 20$ ) at $90{ }^{\circ} \mathrm{C}$ for $5 \mathrm{~min}$. The microwave reactor was digitally programmed to control the experimental conditions, which included a detection system to measure the real-time temperature and power. After the reaction was complete, the mixture was cooled, centrifuged, and dried to a constant weight in an oven. The obtained microcrystalline cellulose was denoted as $\mathbf{M C C}_{\mathbf{M V}}$.

The $\mathbf{M C C}_{\mathbf{M V}}$ was grafted with succinic anhydride via an esterification reaction at a mass ratio of $\mathrm{M}_{\mathrm{MCCMV}}: \mathrm{M}_{\mathrm{SA}}=1: 4$ for $6 \mathrm{~h}$ in order to obtain the $\mathrm{SA}-\mathrm{MCC}_{\mathrm{MV}}$. The reaction was carried out at $120{ }^{\circ} \mathrm{C}$ in the microreaction kettle under reflux in DMF ( $1 \mathrm{~g}$ of MCC: $10 \mathrm{~mL}$ of DMF) after grinding and mixing. Continuous stirring was always applied in the reaction process. The modified cellulose was washed in a soxhlet apparatus with ethanol for $6 \mathrm{~h}$ to remove the unreacted SA and finally washed in sequence with ethanol, deionized water, saturated sodium bicarbonate deionized water, ethanol, and acetone.
Furthermore, $5.0 \mathrm{~g}$ of SA-MCC $\mathrm{MV}_{\mathrm{MV}}$ and $25 \mathrm{~mL}$ of PEI (20 wt\%) (5 equiv. $\mathrm{m} / \mathrm{v}$ ) were placed into the flask within $50 \mathrm{~mL}$ of dimethylformamide (DMF), and then $50 \mathrm{~mL}$ of glutaraldehyde 2.5 $\mathrm{wt} \%)(1: 10 \mathrm{~m} / \mathrm{v})$ was added dropwise to the above mixture over $30 \mathrm{~min}$. Continuous stirring was always applied in the reaction process. After $3 \mathrm{~h}$, the reaction mixture was separated using a table centrifuge and the product was washed with ethanol/ water $(80 / 20 \mathrm{v} / \mathrm{v})$ and deionized water to obtain PEI/SA$\mathrm{MCC}_{\mathrm{MV}}$. The obtained product was ground into a powder for the experiments.

\section{Characterization of PEI/SA-MCC ${ }_{M V}$}

An FTIR type Vertex 70 by Bruker Optics (Germany) was used to identify the surface groups of the synthesized biosorbent. The FTIR spectra were recorded at a resolution of $4 \mathrm{~cm}^{-1}$ from 400 to $4000 \mathrm{~cm}^{-1}$ and 100 scans per sample.

The surface and fracture section of the biosorbent was observed using a scanning electron microscope (SEM) by Phenom (Netherlands). The surface of the biosorbent was coated with gold to be observed and photographed.

Thermogravimetric (TG) analysis (NETZSCH, Germany) was carried out in an $\mathrm{N}_{2}$ atmosphere with a flow rate of $20 \mathrm{~mL} \mathrm{~min}^{-1}$ using $10 \mathrm{mg}$ of the sample over a temperature range of 25-600 ${ }^{\circ} \mathrm{C}$ at a heating rate of $10{ }^{\circ} \mathrm{C} \mathrm{min}^{-1}$.

$\mathrm{X}$-ray photoelectron spectroscopy (XPS) measurements were performed on a Lebold Max200 instrument (Thermo Fisher Scientific, American) using monochromatic 12 (or 15) kV, 15-25 $\mathrm{mA} \mathrm{Al} \mathrm{K}$ radiation to determine the elemental compositions of the samples.

The degree of amination was investigated by measuring the amount of introduced amine functional groups. ${ }^{13,14}$ The content of amine groups was investigated using a back titration method. The sample $(0.1000 \mathrm{~g})$ was treated with a standard solution of $10 \mathrm{mmol} \mathrm{L}^{-1}$ aqueous $\mathrm{HCl}(100.0 \mathrm{~mL})$ in a $250 \mathrm{~mL}$ Erlenmeyer for $1 \mathrm{~h}$ under mechanic stirring. Soon after, the mixture was separated by a single filtration step, and three $25.00 \mathrm{~mL}$ samples were titrated to a phenolphthalein end-point with a standard solution of $10 \mathrm{mmol} \mathrm{L}^{-1}$ aqueous $\mathrm{NaOH}$. The concentration of amine groups was calculated using eqn (1):

$$
C_{\mathrm{NH}, \mathrm{NH}_{2}}=\frac{C_{\mathrm{HCl}} V_{\mathrm{HCl}}-4 C_{\mathrm{NaOH}} V_{\mathrm{NaOH}}}{m}
$$

where $C_{\mathrm{HCl}}\left(\mathrm{mmol} \mathrm{L}^{-1}\right)$ is the concentration of the standard solution of $\mathrm{HCl}, C_{\mathrm{NaOH}}\left(\mathrm{mmol} \mathrm{L}^{-1}\right)$ is the concentration of the standard solution of $\mathrm{NaOH}, V_{\mathrm{HCl}}(\mathrm{L})$ is the volume of the $\mathrm{HCl}$ solution, $V_{\mathrm{NaOH}}(\mathrm{L})$ is the volume of the $\mathrm{NaOH}$ solution spent in the titration of the excess unreacted acid, and the modified cell is the mass $(\mathrm{g})$ of the analyzed sample.

\section{Batch adsorption experiments}

In order to investigate the adsorption performance of the adsorbent towards $\mathrm{Cd}$ (II) and $\mathrm{Pb}$ (II), the effects of $\mathrm{pH}$, the adsorption time and initial concentration were explored. Furthermore, $0.1 \mathrm{~g}$ of the biosorbent was added into $100 \mathrm{~mL}$ of a solution containing the metal ions in a $250 \mathrm{~mL}$ flask and then, the flask was placed in a WY103-B constant temperature shaker 
and stirred for a set time. The adsorption experiment was averaged three times. The metal ion concentration was analyzed using inductively coupled plasma optical emission spectroscopy (ICP-OES) (Agilent Technologies 7000, USA). Adsorption capacity of modified cellulose $\left(\mathrm{mg} \mathrm{g}^{-1}\right)$ was calculated as follows:

$$
Q_{\mathrm{e}}=\frac{C_{0}-C_{1}}{M} V
$$

where $C_{0}$ and $C_{1}$ are the initial and the equilibrium concentrations ( $\mathrm{mg} \mathrm{L}^{-1}$ ), and $M$ and $V$ are the weight of the adsorbent (g) and the volume of the solution (L), respectively.

The adsorbent was added into a heavy metal ion solution at a certain concentration (Cd(II) $200 \mathrm{mg} \mathrm{L}^{-1}$ and $\mathrm{Pb}$ (II) $300 \mathrm{mg} \mathrm{L}^{-1}$ ) at $298 \mathrm{~K}$ and the $\mathrm{pH}$ was adjusted to the set value. To completely dissolve the $\mathrm{Cd}(\mathrm{II})$ and $\mathrm{Pb}$ (II) ions in water, the $\mathrm{pH}$ was designed to range from $\mathrm{pH} 1$ to 6 . The $\mathrm{pH}$ was adjusted via the addition of drops of aqueous $\mathrm{NaOH}$ and/or $\mathrm{HCl}$ solution $\left(0.1-1.0 \mathrm{~mol} \mathrm{~L}^{-1}\right)$. The metal ion uptake capacities were measured as a function of time to determine the optimum contact times for the adsorption of $\mathrm{Cd}(\mathrm{II})$ and $\mathrm{Pb}$ (II) ions. The contact times in the present study were from 15 to $120 \mathrm{~min}$ for Cd(II) and 15 to $180 \mathrm{~min}$ for $\mathrm{Pb}(\mathrm{II})$. While performing the experiments, the samples were withdrawn at pre-determined time intervals and analyzed for metal adsorption. The effect of common co-existing ions (K(I), $\mathrm{Na}(\mathrm{I}), \mathrm{Ca}(\mathrm{II}), \mathrm{Mg}(\mathrm{II}))$ on the $\mathrm{Pb}(\mathrm{II})$ and $\mathrm{Cd}(\mathrm{II})$ adsorption was investigated by maintaining the concentration of $\mathrm{Pb}$ (II) and $\mathrm{Cd}(\mathrm{II})$ and each of the co-existing ion concentration ranges from $0 \mathrm{mg} \mathrm{L}^{-1}$ to $500 \mathrm{mg} \mathrm{L}^{-1}$ [Cd(II) $200 \mathrm{mg} \mathrm{L}^{-1}$ and $\mathrm{Pb}$ (II) $\left.300 \mathrm{mg} \mathrm{L}^{-1}\right]$.

The adsorbent after the first adsorption process was dried following its filtration and isolation and added to a conical flask with $0.1 \mathrm{~mol} \mathrm{~L}^{-1} \mathrm{HNO}_{3}$ solution. Desorption was performed under ultrasonication for $30 \mathrm{~min}$ and then, and washings were repeatedly carried out with water until neutral. The adsorbent was dried and reused for the next adsorption experiment.

\section{Results and discussion}

\section{Synthesis and characterization of the adsorbent}

The synthesis route used to prepare PEI/SA-MCC $\mathrm{MV}_{\mathrm{MV}}$ is shown in Fig. 1. The carboxylic acid functional group was introduced into the cellulose skeleton via an esterification reaction in the first step. The carboxylated cellulose $\left(\mathrm{SA}_{-} \mathrm{MCC}_{\mathrm{MV}}\right)$ was used to synthesize the PEI/SA-MCC ${ }_{\text {MV }}$ sample. In this pathway, glutaraldehyde was used as a coupling agent to graft the hydroxyl groups with polyethyleneimine (PEI). The concentration of the amine functionalities and nitrogen percentage were $2.61 \mathrm{mmol}$ $\mathrm{g}^{-1}$ and $4.88 \%$, respectively, and $2.39 \mathrm{mmol} \mathrm{g}^{-1}$ and $4.71 \%$ individually for the mercerizing pretreatment (for more than 12 h) experiment. Table 1 gives details for the elemental and amino contents of PEI/SA-MCC $\mathrm{MV}_{\mathrm{MV}}$ and PEI/SA-MMCC compared with the PEI/SA-MCC sample with no-pretreatment. The standard deviation was less than 0.5 in these values.

Therefore, it is possible that the $\mathrm{MV}-\mathrm{H}_{2} \mathrm{O}_{2}$-assisted preparation (5 min) used for the preparation of PEI/SA-MCC $\mathrm{MV}_{\mathrm{MV}}$ was efficient and represented an alternative pathway to anchor the amine functional groups onto the succinylated cellulose to form the new adsorbent.

Fig. 2 shows the FT-IR spectra of $\mathrm{MCC}_{\mathrm{MV}}, \mathrm{SA}_{-\mathrm{MCC}_{\mathrm{MV}}}$ and PEI/SA-MCC ${ }_{\text {MV }}$. The absorption peaks at $3349 \mathrm{~cm}^{-1}, 2900 \mathrm{~cm}^{-1}$, $1634 \mathrm{~cm}^{-1}, 1373 \mathrm{~cm}^{-1}, 1160 \mathrm{~cm}^{-1}, 1046 \mathrm{~cm}^{-1}$ and $894 \mathrm{~cm}^{-1}$ are associated with MCC. ${ }^{15}$ The strong adsorption at $3349 \mathrm{~cm}^{-1}$ was due to the stretching of $-\mathrm{OH}$ and at $2900 \mathrm{~cm}^{-1}$ due to aliphatic $\mathrm{C}-\mathrm{H}$ stretching. The peak at $1634 \mathrm{~cm}^{-1}$ was attributed to the bending mode of the absorbed water and $1373 \mathrm{~cm}^{-1}$ to $\mathrm{O}-\mathrm{H}$ bending. The absorption band at $1160 \mathrm{~cm}^{-1}$ corresponds to the C-O anti-symmetric bridge stretching of cellulose, $1046 \mathrm{~cm}^{-1}$ arises from the pyranose ring skeletal vibrations and $894 \mathrm{~cm}^{-1}$ is due to the $\beta$-glucosidic linkages between the sugar units. ${ }^{16,17}$ In the spectrum of succinylated cellulose, $\mathrm{SA}_{\mathrm{MCC}} \mathrm{MV}_{\mathrm{MV}}$, the new peak at $1725 \mathrm{~cm}^{-1}$ was assigned to the asymmetric and symmetric stretching of the ester $\mathrm{C}-\mathrm{O}$ bond, indicating the occurrence of the esterification reaction between cellulose and succinic anhydride during the synthesis. Furthermore, after the modification step, the appearance of the bands at $1598 \mathrm{~cm}^{-1}$, corresponding to the asymmetric stretching vibrations of the ionic carboxylic groups, verified the introduction of carboxylic groups on the surface ${ }^{18}$ (Zhao et al., 2007). Compared with MCC, the FTIR spectra of PEI/SA-MCC ${ }_{M V}$ gives weaker peak intensities at 3438 and $2902 \mathrm{~cm}^{-1}$, which was attributed to the overlap of the stretching vibrations of $\mathrm{NH}_{2}\left(3400\right.$ and $\left.3200 \mathrm{~cm}^{-1}\right)$ with the characteristic peak of cellulose at $3349 .{ }^{19}$ Another peak at 1130 $\mathrm{cm}^{-1}$ indicated the stretching frequency of the secondary amine group from PEI.

The TG curve obtained for $\mathrm{MCC}_{\mathrm{MV}}$ shows three stage decompositions. A 6\% mass loss because of the evaporation of moisture, including free water, physically absorbed water and bound water at the initial stage before $100{ }^{\circ} \mathrm{C} .{ }^{19}$ The second stage was the main stage of the decomposition, and an $80.5 \%$ mass loss at $320-450{ }^{\circ} \mathrm{C}$ was attributed to the carbonizationcracking of cellulose and the formation of carbonaceous residues. The long chains of cellulose were broken and the structure was split into low molecules. Moreover, $350{ }^{\circ} \mathrm{C}$ was the temperature characteristic of weightlessness of microcrystalline cellulose. For PEI/SA-MCC ${ }_{\mathrm{MV}}$, an $11 \%$ weight loss was observed in the initial stage. The second stage occurred in the range of $320-500{ }^{\circ} \mathrm{C}$ with a mass loss of $63.05 \%$ due to the pyrolytic decomposition of the PEI polymer as well as the chain scissions of the grafted polymer. In the process of weightlessness, two inflection points at $350{ }^{\circ} \mathrm{C}$ and $500{ }^{\circ} \mathrm{C}$ were observed in the curve, and the thermal degradation temperature was elevated, indicating that the graft polymerization reaction was successful, and the adsorbent had a higher thermal stability than the parent compounds (Fig. 3).

The $\mathrm{C}$ 1s peak corresponds to two main components, C-N and $\mathrm{C}-\mathrm{O}$, with the binding energy peaks at 283.4 and $284.8 \mathrm{eV}$. $^{3}$ The emergence of $\mathrm{C}-\mathrm{N}$ demonstrates that PEI already existed in the chelating materials. The N 1s XPS spectrum can be fitted into three peaks with the binding energy peaks at $397.1,398.1$ and $399.9 \mathrm{eV}$ due to the $\mathrm{R} 2 \mathrm{NH}, \mathrm{RNH}_{2}$ and $\mathrm{R} 3 \mathrm{~N}$ groups, respectively. ${ }^{20}$ The oxygen-containing groups were determined by the O 1s XPS spectra. These could be fitted into two peaks with the binding energy at 531.1 and $532.2 \mathrm{eV}$, which were attributed to 

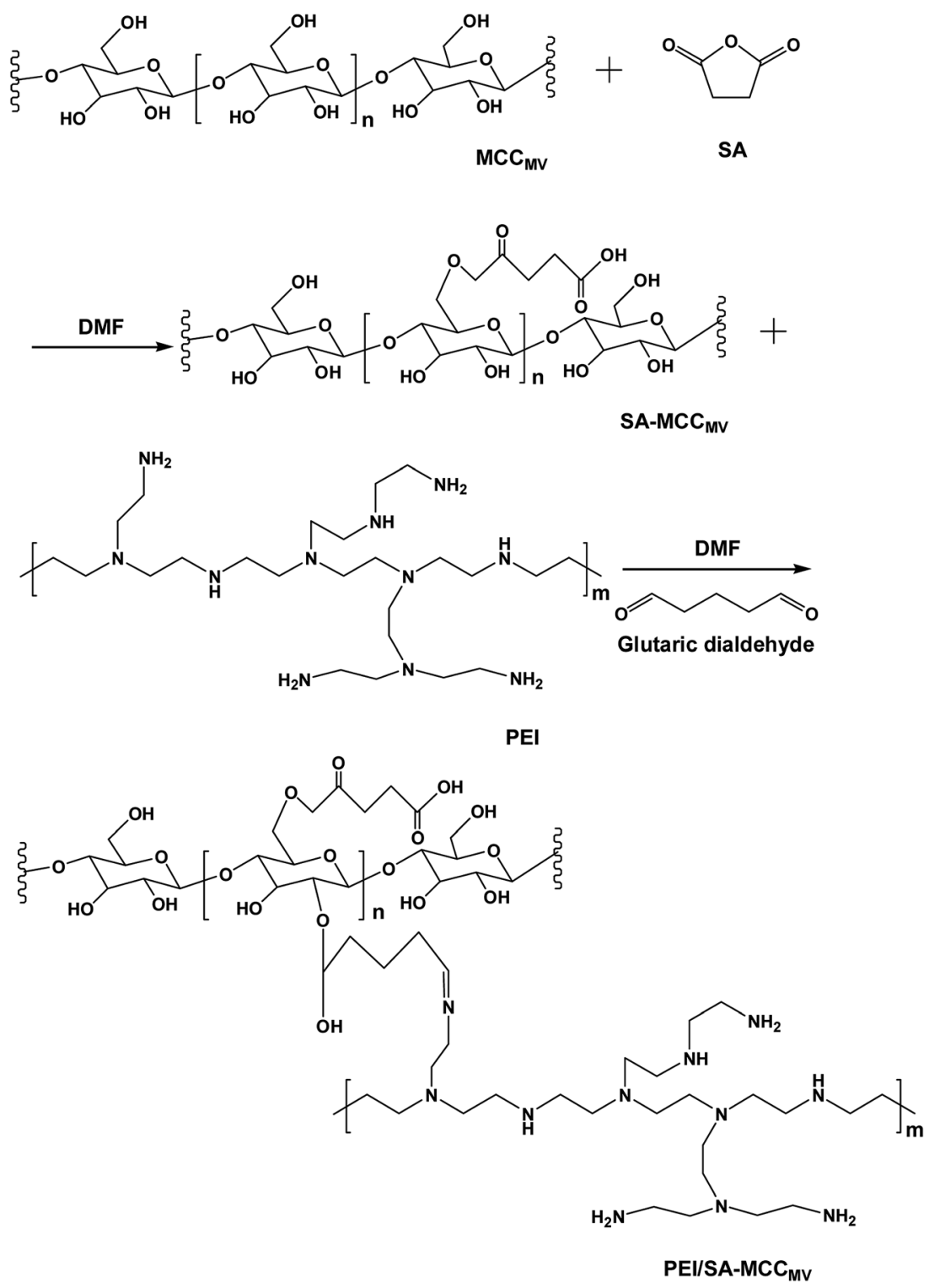

Fig. 1 The synthesis route used to prepare PEI/SA-MCC ${ }_{M V}$.

Table 1 The elemental contents measured using XPS and the amino content of $\mathrm{MCC}_{M V}, \mathrm{PEI} / \mathrm{SA}-\mathrm{MCC}, \mathrm{PEI} / \mathrm{SA}-\mathrm{MMCC}$, and PEI/SA-MCC ${ }_{M V}{ }^{a}$

\begin{tabular}{lllll}
\hline Sample & $\begin{array}{l}\text { C 1s } \\
(\mathrm{wt} \%)\end{array}$ & $\begin{array}{l}\text { O 1s } \\
(\mathrm{wt} \%)\end{array}$ & $\begin{array}{l}\text { N 1s } \\
(\mathrm{wt} \%)\end{array}$ & $\begin{array}{l}\text { Amino content } \\
\left(\mathrm{mmol} \mathrm{g}^{-1}\right)\end{array}$ \\
\hline MCC $_{\text {MV }}$ & 73.22 & 26.78 & - & - \\
PEI/SA-MCC & 79.81 & 17.60 & 2.59 & 1.27 \\
PEI/SA-MMCC $_{\text {PEI/SA-MCC }}$ & 74.66 & 20.63 & 4.71 & 2.39 \\
MV & 75.83 & 19.29 & 4.88 & 2.61
\end{tabular}

${ }^{a}$ PEI/SA-MCC: no pretreatment, PEI/SA-MMCC: mercerizing pretreatment.

the $\mathrm{C}=\mathrm{O}$ and $\mathrm{C}-\mathrm{O}$ groups. ${ }^{21}$ These also indicated that MCC had been modified with PEI by cross-linking the $\mathrm{RNH}_{2}$ groups of PEI with the $-\mathrm{OH}$ groups of cellulose, which was consistent with the

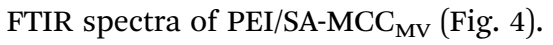

The SEM images of MCC $(1 ; \times 8000)$ and PEI/SA-MCC ${ }_{M V}(2$; $\times 8000)$ in Fig. 5 clearly show that the surface morphology of MCC had changed greatly after the modification step. For MCC $(1 ; \times 8000)$, its surface was relatively smooth, while for PEI/SA$\mathrm{MCC}_{\mathrm{MV}}(2 ; \times 8000)$, its surface was more rough and displayed a gap of honeycomb structure. The rough surface of PEI/SA$\mathrm{MCC}_{\mathrm{MV}}(2 ; \times 8000)$ revealed that the order of MCC was reduced during its synthesis.

\section{Adsorption studies of $\mathrm{Cd}(\mathrm{II})$ and $\mathrm{Pb}$ (II)}

The $\mathrm{pH}$ value impacted the adsorption equilibrium and adsorption kinetics of heavy metals in water because the $\mathrm{pH}$ of the solution not only affects the hydrogen ion concentration of the surface functional groups but also has a great influence on the metal ions ionization. ${ }^{18}$ Therefore, it is necessary to find the optimum $\mathrm{pH}$ value in order to maximize the adsorption capacity of the adsorbents. The effect of $\mathrm{pH}$ on the adsorption of $\mathrm{Cd}(\mathrm{II})$ 


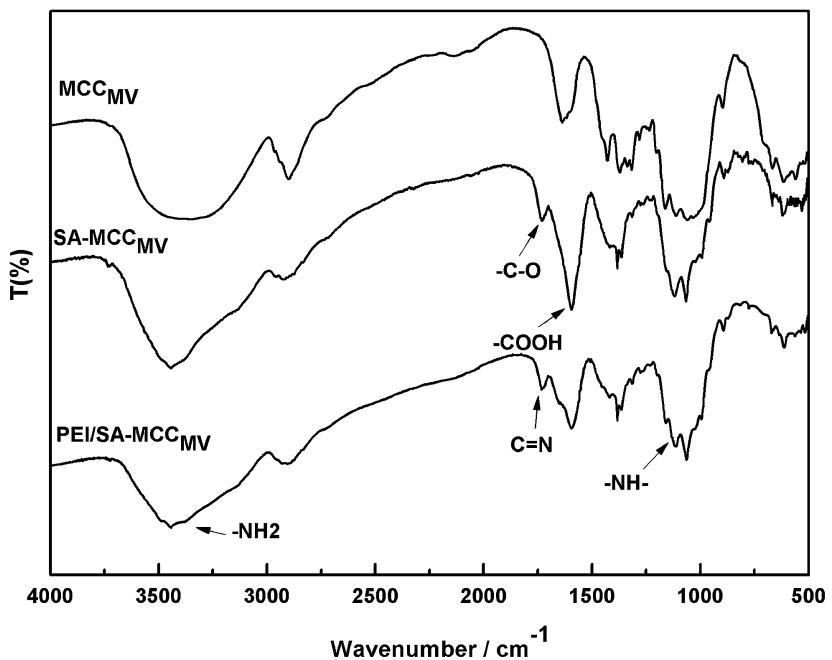

Fig. 2 The FT-IR spectra of $M C C_{M V}, S A-M C C_{M V}$ and PEI/SA-MCC $M$.

and $\mathrm{Pb}$ (II) is shown in Fig. 6 . When the $\mathrm{pH}$ values were at $\mathrm{pH} 2-5$ for $\mathrm{Pb}$ (II) and $\mathrm{pH}$ 3-6 for $\mathrm{Cd}$ (II), the higher the $\mathrm{pH}$ value was, the stronger the equilibrium adsorption capacity was. This can be attributed to the production of competitive adsorption between $\mathrm{H}^{+}$and the metal ions for the active sites. At lower $\mathrm{pH}$ values, the high $\mathrm{H}^{+}$concentration would intensify the competition and repulsion between $\mathrm{H}^{+}$and the metal ions for the active sites on the surface of the biosorbent. At higher $\mathrm{pH}$, the active sites passivated by $\mathrm{H}^{+}$were released, and the adsorption was enhanced. The optimal $\mathrm{pH}$ value was 5.0 for $\mathrm{Pb}(\mathrm{II})$ and 5.6 for Cd(II).

The adsorption equilibrium was investigated. The results in Fig. 7 show that the adsorption equilibrium was attained after 20 min for $\mathrm{Cd}(\mathrm{II})$ and $45 \mathrm{~min}$ for $\mathrm{Pb}$ (II). During this short contact time, the adsorption was very fast due to the presence of numerous active sites on the adsorbent surface. The adsorption effect was not significantly improved after the equilibrium time because the active sites were almost occupied by the metal ions on the surface of the adsorbent. However, the adsorption rate still had a small increase. This indicated that some of the metal ions were instantly adsorbed and after further mixing, new adsorption sites became available possibly due to the diffusion of metal ions inside the pores of the cellulosic material.

\section{Adsorption kinetic study}

The adsorption kinetic experimental results for $\mathrm{Pb}$ (II) and $\mathrm{Cd}(\mathrm{II})$ are illustrated in Fig. 8. The pseudo second-order model was adopted to investigate the kinetic mechanism. The correlation coefficients $\left(R^{2}\right)$ for $\mathrm{Pb}(\mathrm{II})$ and $\mathrm{Cd}(\mathrm{II})$ were both larger than 0.99 , which indicated that this model can depict the adsorption processes well. In addition, the results also suggest that the adsorption process was chemical adsorption. Table 2 shows the results of the different fitting models. The practical value $\left(Q_{\mathrm{e}}\right.$-exp) was consistent with the theoretical value $\left(Q_{\mathrm{e}}\right.$-model). The pseudo first-order model and pseudo second-order model equations are as follows: ${ }^{22}$

$$
\begin{gathered}
Q_{t}=Q_{\mathrm{e}}\left(1-\mathrm{e}^{-K_{1} t}\right) \\
\frac{t}{Q_{t}}=\frac{1}{k_{2} Q_{\mathrm{e}}{ }^{2}}+\frac{t}{Q_{\mathrm{e}}}
\end{gathered}
$$

where $Q_{\mathrm{e}}$ is the equilibrium adsorption capacity, $\mathrm{mg} \mathrm{g}^{-1} ; Q_{t}$ is the adsorption capacity at time $t, \mathrm{mg} \mathrm{g}^{-1} ; K_{1}$ is the pseudo second-order adsorption rate constant, $\min ^{-1}$ and $K_{2}$ is the pseudo second-order adsorption rate constant, $\mathrm{g} \mathrm{mg}^{-1} \mathrm{~min}$.

\section{Adsorption isotherms study}

Adsorption isotherms, which describe how an adsorbate interacts with the adsorbent are critical for optimizing the application of an adsorbent. The adsorption process was fitted by the Langmuir, Freundlich and Temkin models. The Langmuir isotherm model describes a type of ideal monolayer adsorption and has some assumptions; for example, the active sites are uniformly distributed, the adsorbate molecules are very small compared with the active sites and the interactions between the adsorbed molecules and adsorbent are homogeneous. The Langmuir isotherm is widely applied in physical adsorption and chemical adsorption processes. It can be expressed by eqn (5) and can be rearranged to obtain its linearized form, as shown in eqn (6).
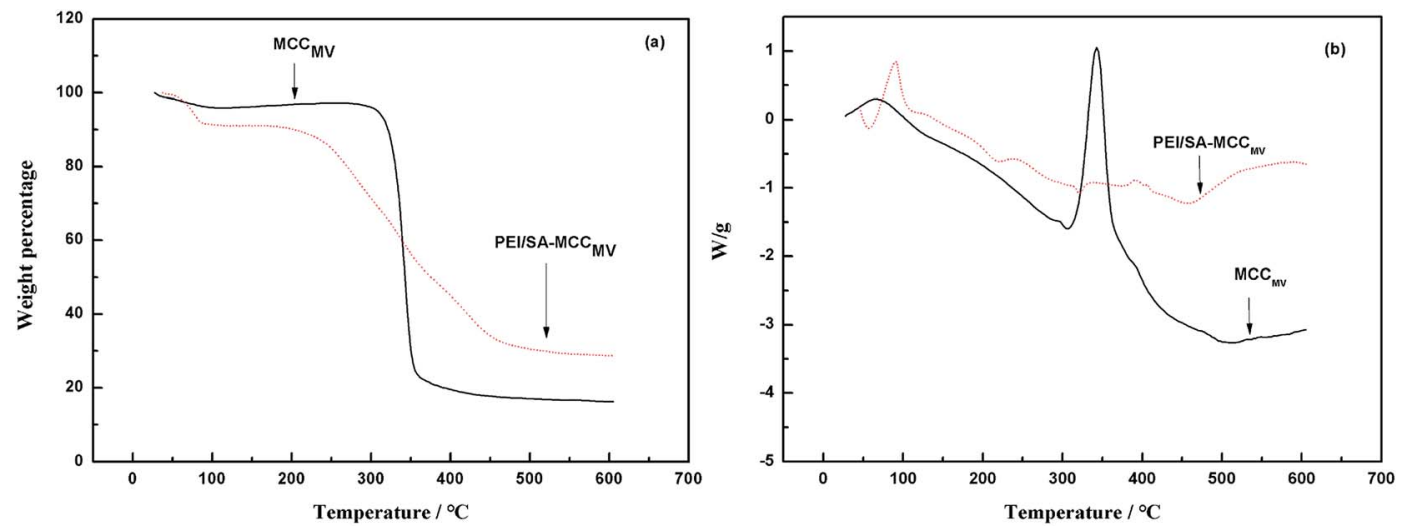

Fig. 3 The TG (a) and DSC (b) curves obtained for $M_{C C} C_{M V}$ and PEI/SA-MCC $M$. 

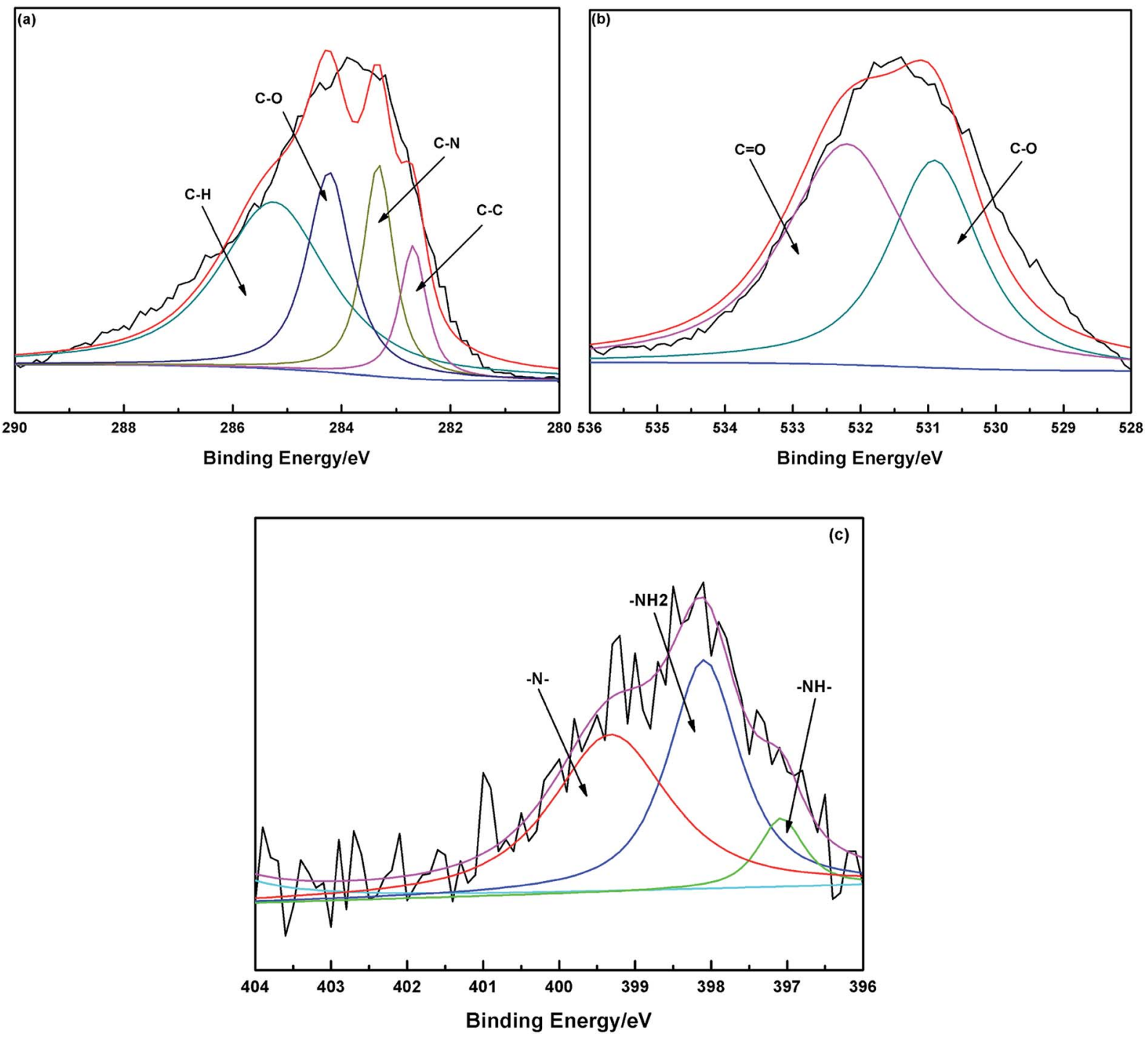

Fig. 4 The $C$ 1s (a), $O 1 s$ (b) and $N$ 1s (c) XPS spectra of PEI/SA-MCC $M V$.

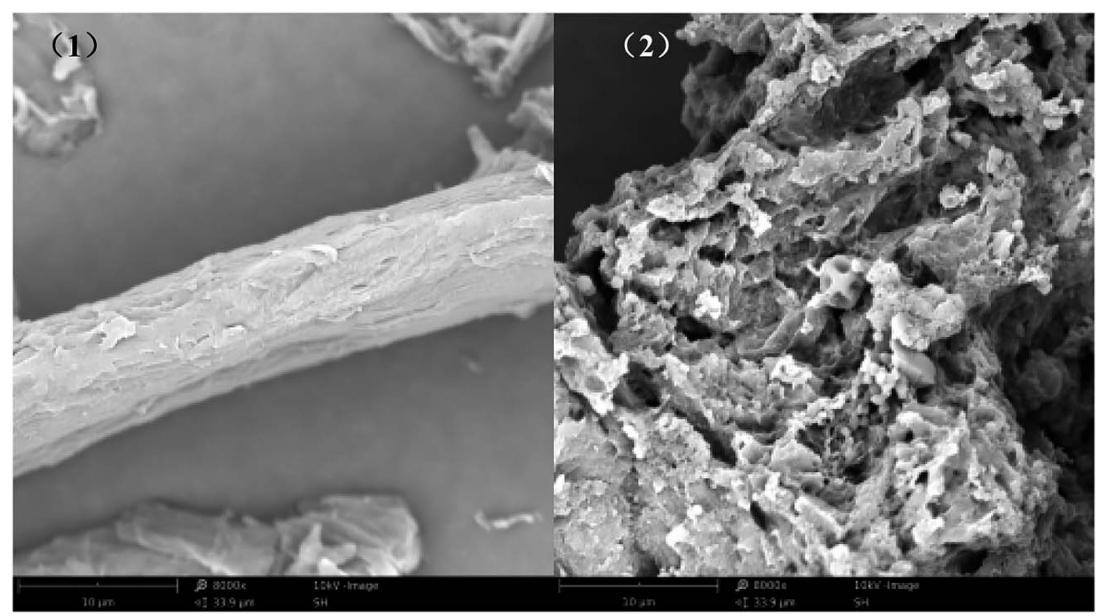

Fig. 5 The SEM images of MCC $(1 ; \times 8000)$ and PEI/SA-MCC $M V(2 ; \times 8000)$. 


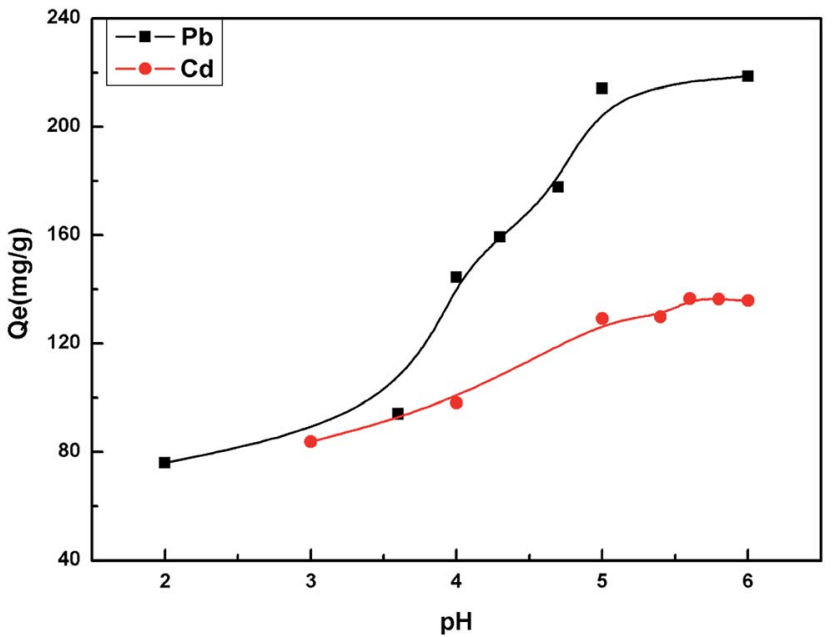

Fig. 6 The effects of $\mathrm{pH}$ on the adsorption of metal ions.

$$
\begin{gathered}
Q_{\mathrm{e}}=\frac{Q_{\mathrm{m}} K_{\mathrm{L}} C_{\mathrm{e}}}{1+K_{\mathrm{L}} C_{\mathrm{e}}} \\
\frac{C_{\mathrm{e}}}{Q_{\mathrm{e}}}=\frac{1}{Q_{\mathrm{m}} K_{\mathrm{L}}}+\frac{C_{\mathrm{e}}}{Q_{\mathrm{m}}}
\end{gathered}
$$

where $Q_{\mathrm{e}}\left(\mathrm{mg} \mathrm{g}^{-1}\right)$ is the equilibrium adsorption capacity, $Q_{\mathrm{m}}$ $\left(\mathrm{mg} \mathrm{g}^{-1}\right)$ is the maximum amount of the metal ion per unit weight of the modified cellulose to form a complete monolayer coverage on the surface bound at a high equilibrium metal ion concentration $C_{\mathrm{e}}\left(\mathrm{mg} \mathrm{L}^{-1}\right)$, and $K_{\mathrm{L}}\left(\mathrm{L} \mathrm{mg}^{-1}\right)$ is the Langmuir constant related to the binding sites affinity.

However, for non-ideal adsorption phenomenon, the Langmuir model is usually too simple to describe ${ }^{11}$ because the surface active sites of non-ideal adsorption are not evenly distributed, and the interactions between the adsorbent and adsorbate are uneven. For the Freundlich isotherm model, the heterogeneous absorptive energies are considered on the surface of the absorbent and describe the adsorption on a homogeneous surface using a multi-layer adsorption

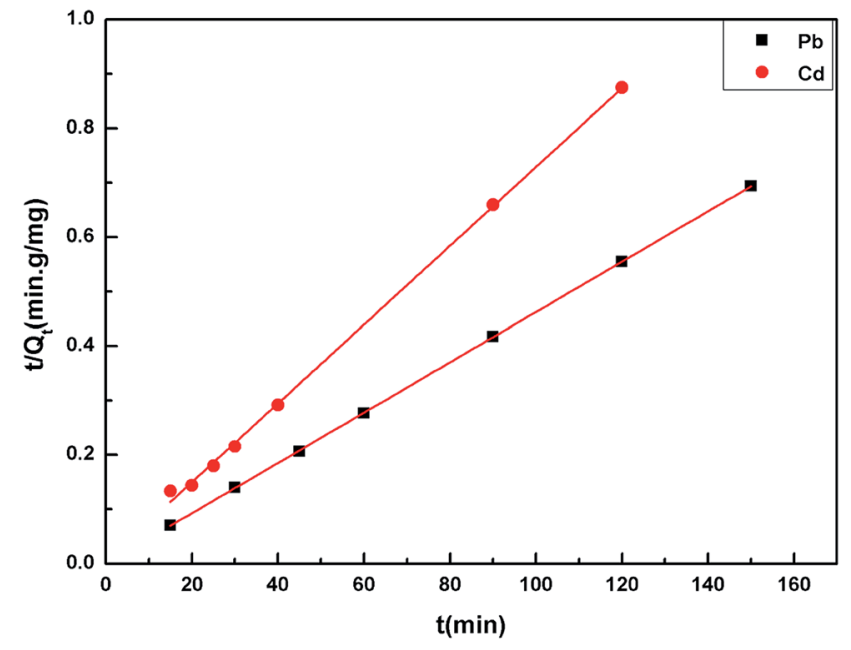

Fig. 8 The pseudo second-order kinetics for $\mathrm{Pb}(॥)$ and $\mathrm{Cd}(\Perp)$ adsorption.

Table 2 The kinetics model parameters for $\mathrm{Cd}(॥)$ and $\mathrm{Pb}(॥)$ adsorption on PEI/SA-MCC ${ }_{M V}$

\begin{tabular}{llllllll}
\hline & & \multicolumn{3}{c}{ Value } & & \multicolumn{2}{l}{$R^{2}$} \\
Kinetic model & Parameter & $\mathrm{Pb}(\mathrm{II})$ & $\mathrm{Cd}(\mathrm{II})$ & & $\mathrm{Pb}(\mathrm{II})$ & $\mathrm{Cd}(\mathrm{II})$ \\
\hline \multirow{2}{*}{ Pseudo-first-order } & $K_{1}$ & 0.2879 & 0.1350 & 0.3893 & 0.5709 \\
& $Q_{\mathrm{e}}$ & 216.2304 & 139.5909 & & \\
Pseudo-second-order & $K_{2}$ & 0.2100 & 0.0102 & 0.9999 & 0.9995 \\
& $Q_{\mathrm{e}}$ & 217.3913 & 138.8888 & & \\
& & & & &
\end{tabular}

mechanism. The Freundlich isotherm model is described by eqn (7) and can be rearranged to obtain its linearized form, as shown in eqn (8).

$$
\begin{gathered}
Q_{\mathrm{e}}=K_{\mathrm{F}} C_{\mathrm{e}}^{\frac{1}{n}} \\
\ln Q_{\mathrm{e}}=\frac{1}{n} \ln C_{\mathrm{e}}+\ln K_{\mathrm{F}}
\end{gathered}
$$
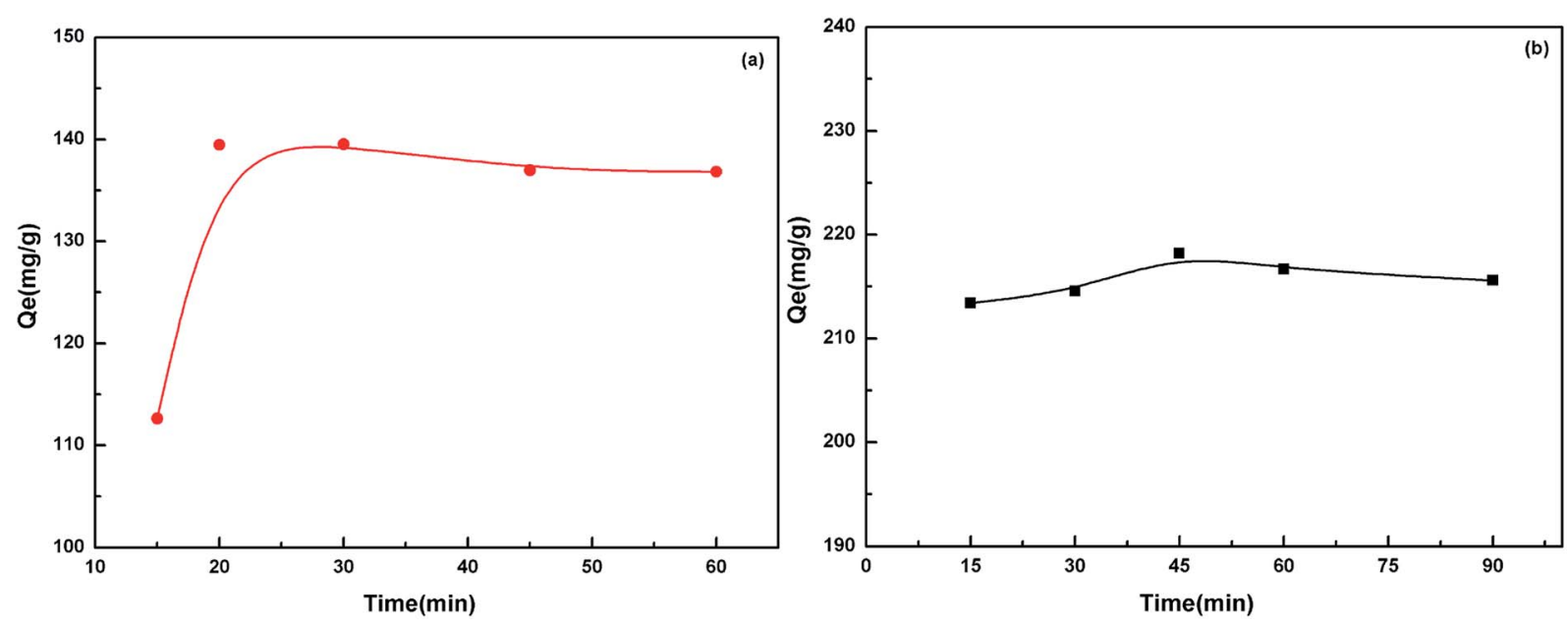

Fig. 7 The effects of time on the adsorption of $\mathrm{Cd}(\Perp)$ (a) and $\mathrm{Pb}(॥)(\mathrm{b})$. 
where $K_{\mathrm{F}}$ and $1 / n$ are the Freundlich constants.

Moreover, in the Tempkin model of adsorption and the adsorbent-adsorbate interactions on the adsorption isotherms were studied by Tempkin and Pyzhev, who suggested that because of these interactions, the energy of adsorption of all the molecules decreases linearly with coverage. The Temkin isotherm is represented by following equation:

$$
Q_{\mathrm{e}}=B \ln A+B \ln C_{\mathrm{e}}
$$

where $A$ is the equilibrium constant of the maximum adsorption capacity, and $B$ is the Tempkin isotherm constant.

The linearized plots of $C_{\mathrm{e}} / Q_{\mathrm{e}}$ versus $C_{\mathrm{e}}$ and $\ln Q_{\mathrm{e}}$ versus $\ln C_{\mathrm{e}}$ were obtained from the models and are shown in Fig. 9. The parameters $Q_{\mathrm{m}}, K_{\mathrm{L}}, n$ and $K_{\mathrm{F}}$, and $A$ and $B$ are given in Table 3 . The degrees of freedom for the two models were both four. The correlation coefficient was comparable. The correlation coefficient indicated that the Freundlich mode $\left(R^{2}>0.999\right)$ could explain the adsorption process for the $\mathrm{Cd}(\mathrm{II})$ and $\mathrm{Pb}$ (II) ions better. The sum of the squared residuals was smaller, and hence
Table 3 A comparison of the linear fitting parameters of the Langmuir, Freundlich and Temkin models used for the adsorption of the biosorbent towards metal ions

\begin{tabular}{|c|c|c|c|c|c|}
\hline \multirow{2}{*}{$\begin{array}{l}\text { Isotherm } \\
\text { model }\end{array}$} & \multirow[b]{2}{*}{ Parameter } & \multicolumn{2}{|l|}{ Value } & \multicolumn{2}{|l|}{$R^{2}$} \\
\hline & & $\mathrm{Pb}(\mathrm{II})$ & $\mathrm{Cd}(\mathrm{II})$ & Pb(II) & Cd(II) \\
\hline \multirow[t]{2}{*}{ Langmuir } & $K_{\mathrm{L}}$ & 0.0028 & 0.0054 & 0.9113 & 0.9000 \\
\hline & $Q_{\mathrm{m}}$ & 357.14 & 217.39 & & \\
\hline \multirow[t]{2}{*}{ Freundlich } & $K_{\mathrm{F}}$ & 4.0386 & 3.7558 & 0.9994 & 0.9995 \\
\hline & $n$ & 1.3959 & 1.3233 & & \\
\hline \multirow[t]{2}{*}{ Temkin } & $B$ & 59.251 & 35.287 & 0.93475 & 0.9516 \\
\hline & $A$ & 0.0426 & 0.0740 & & \\
\hline
\end{tabular}

the fitting effect was better. The residual sum of squares in the Freundlich model was smaller than that in the Langmuir model, which also indicated that the former was more appropriate. For a further explanation, it is necessary to consider the coordination chemistry of the ligand groups contained in the adsorbent. During the chelation process, a metal ion forms
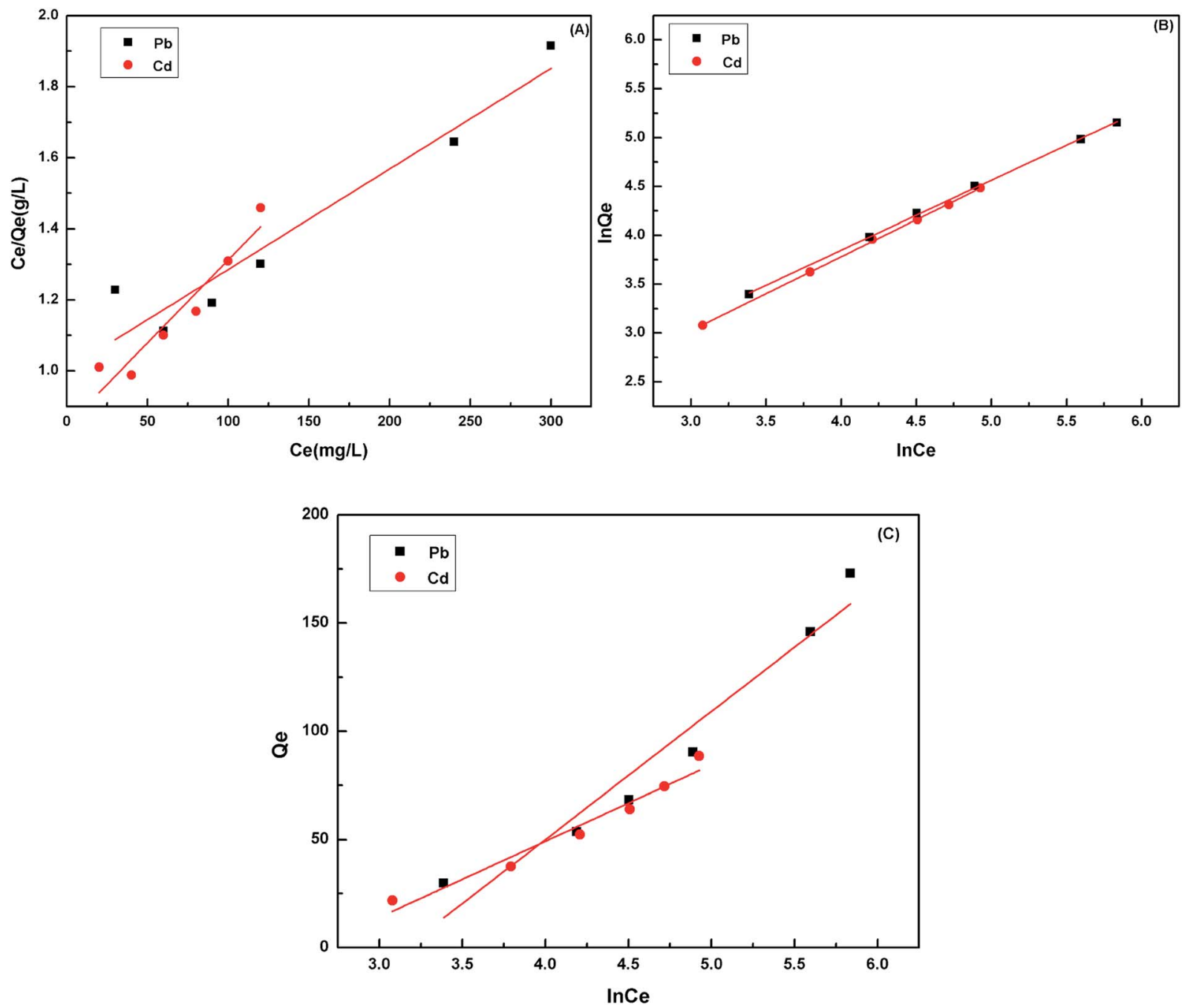

Fig. 9 The Langmuir isotherm plots obtained for $\mathrm{Pb}(॥)$ and $\mathrm{Cd}(॥)(\mathrm{A})$; the Freundlich isotherm plots obtained for $\mathrm{Pb}(\|)$ and $\mathrm{Cd}(॥)(\mathrm{B})$ and the $\mathrm{Temkin}$ isotherm plots obtained for $\mathrm{Pb}(I)$ and $\mathrm{Cd}(॥)(\mathrm{C})$. 
a coordination bond with the electron pair of the negatively charged oxygen atom in the carboxylate groups to satisfy its primary valence as well as with the unshared electron pair of the nitrogen atom in the polyamine to satisfy its secondary valence.

The adsorption capacities of cell 5 on $\mathrm{Pb}$ (II) and $\mathrm{Cd}(\mathrm{II})$ calculated using the Langmuir model were 357.14 and $217.39 \mathrm{mg} \mathrm{g}^{-1}$ at $298 \mathrm{~K}$, respectively (Table 3), all of which were much higher than those of raw microcrystalline cellulose (27.0 and $16.0 \mathrm{mg} \mathrm{g}^{-1}$ ). Interestingly, the $Q_{\max }$ towards $\mathrm{Pb}(\mathrm{II})$ was higher than $\mathrm{Cd}(\mathrm{II})$, which was due to the fact that the lower hydration energy of $\mathrm{Pb}$ (II) could help the ions react with the activated sites of the biosorbent.

The reusability of an adsorbent is one of the most important parameters for its practical application. Desorption experiments were also conducted using the bath method. The adsorptiondesorption cycle of PEI/SA-MCC $\mathrm{MV}_{\mathrm{MV}}$ was repeated five times, and the results are shown in Fig. 10. It can be seen that PEI/SA-MCC $\mathrm{MV}_{\mathrm{MV}}$ retains a good adsorption performance (56\% removal efficiency of $\mathrm{Pb}(\mathrm{II}), 54 \%$ removal efficiency of $\mathrm{Cd}(\mathrm{II}))$ after five recycles.

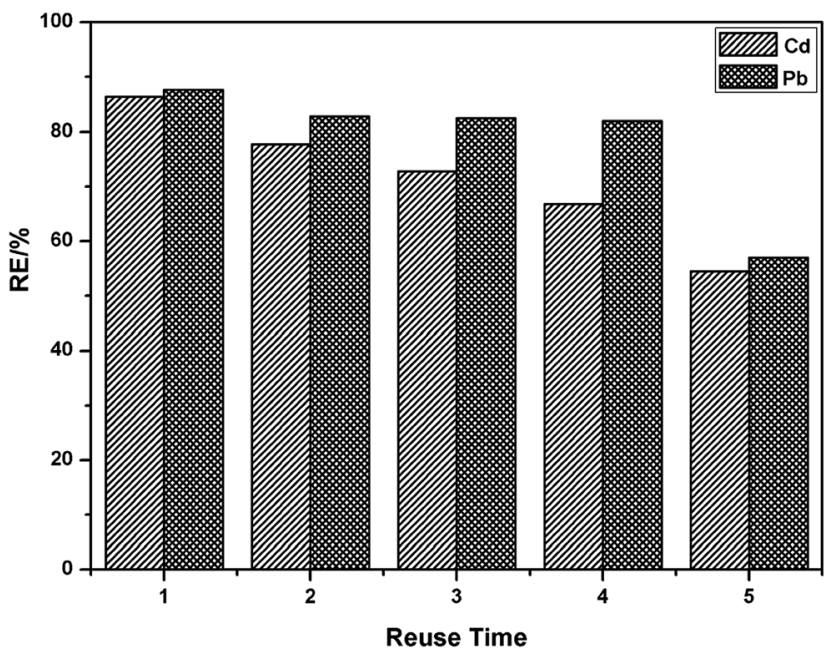

Fig. 10 The regeneration of PEI/SA-MCC ${ }_{M V}$.
Table 4 A comparison of the adsorption capacity between PEI/SA$\mathrm{MCC}_{\mathrm{MV}}$ and other previously reported adsorbents

\begin{tabular}{lllll}
\hline & \multicolumn{3}{c}{$Q_{\max }\left(\mathrm{mg} \mathrm{g}^{-1}\right)$} & \\
\cline { 3 - 4 } Adsorbents & $\mathrm{pH}$ & $\mathrm{Pb}(\mathrm{II})$ & $\mathrm{Cd}(\mathrm{II})$ & Ref \\
\hline CMJF $_{\text {MH }}$ & 6 & 157.21 & 88 & 17 \\
Chitosan/cotton fibers & 6.5 & 101.53 & 15.74 & 23 \\
Spirodela polyrhiza & 6 & - & 36.00 & 24 \\
Spirodela polyrhiza & 4 & 137.00 & - & 24 \\
PEI/SA-MCC $_{\text {MV }}$ & 5 & 218.20 & - & This paper \\
PEI/SA-MCC & 5.6 & - & 139.47 & This paper \\
& & & &
\end{tabular}

The effect of common co-existing ions (K(I), $\mathrm{Na}(\mathrm{I}), \mathrm{Ca}(\mathrm{II})$ and $\mathrm{Mg}(\mathrm{II}))$ on the adsorption of $\mathrm{Pb}$ (II) and $\mathrm{Cd}(\mathrm{II})$ was investigated by maintaining the concentration of $\mathrm{Pb}$ (II) and $\mathrm{Cd}$ (II) and each of the co-existing ions concentration ranged from 0 to $500 \mathrm{mg} \mathrm{L}^{-1}$, as shown in Fig. 11. It was clear that the co-existing ions exhibited a slight competition for the active sites due to the high affinity between the co-existing ions and the active sites. The active sites of the adsorbent surface are limited, which results in the competitive adsorption.

In addition, comparative experiments between PEI/SA$\mathrm{MCC}_{\mathrm{MV}}$ and other previously reported adsorbents were investigated to illustrate the excellent adsorption performance of PEI/ SA-MCC $\mathrm{MV}_{\mathrm{MV}}$, as shown in Table 4. The results indicate that the maximum adsorption capacities of PEI/SA-MCC $\mathrm{MV}_{\mathrm{MV}}$ for $\mathrm{Pb}$ (II) and Cd(II) were significantly higher those reported for the other previously reported adsorbents. The simple synthesis method and efficient removal efficiency will lead to a broad range of potential applications.

\section{Adsorption mechanism}

According to the aforementioned results, the enhanced metal ion adsorption capacity of PEI/SA-MCC $\mathrm{MV}_{\mathrm{MV}}$ may be attributed to the introduction of $-\mathrm{NH}_{2}$ and $-\mathrm{COOH}$ groups on the cellulose surface, and the main mechanism for $\mathrm{Cd}(\mathrm{II})$ and $\mathrm{Pb}$ (II) removal is chelating adsorption. The amino groups are mainly responsible for the uptake of metal ions as follows: ${ }^{25}$
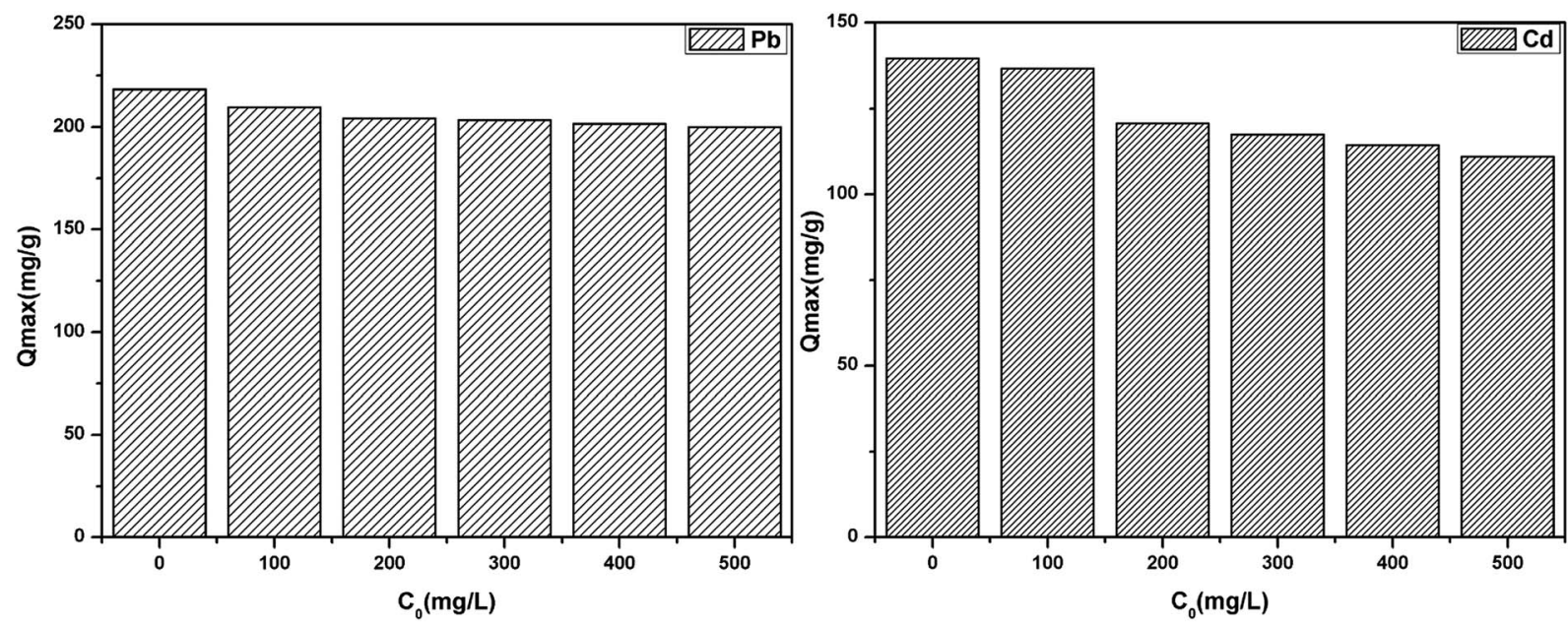

Fig. 11 The effect of common co-existing ions on the adsorption of $\mathrm{Pb}(I)$ and $\mathrm{Cd}(॥)$. 


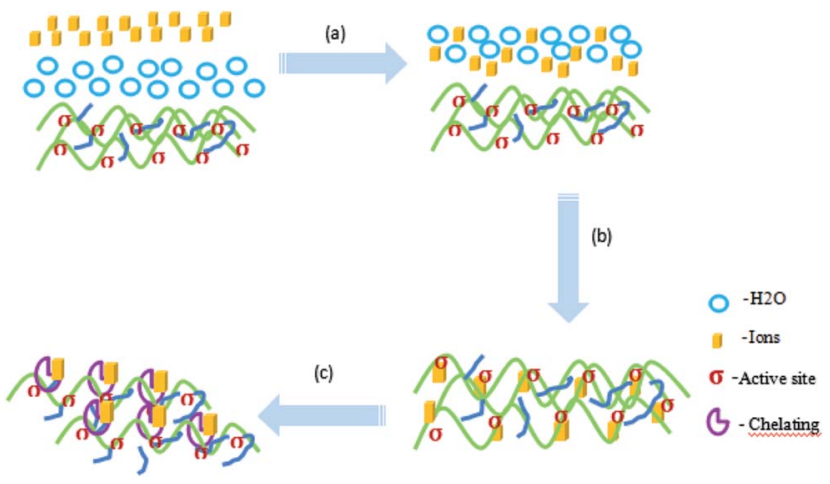

Fig. 12 The probable adsorption mechanism $\left(\mathrm{M}^{n+}\right.$ - Metal ions; $\sigma-$ Active site).

$$
\mathrm{M}^{2+}+\mathrm{RNH}_{2}^{+} \rightarrow \mathrm{M}\left(\mathrm{RNH}_{2}\right)^{2+}
$$

In consideration of the main existing forms of these heavy metal ions in an aqueous solution, the probable adsorption mechanism can be expressed in three steps ${ }^{26,27}$ (Liu, 2015a; Liu, 2015b), as shown in Fig. 12: (a) the adsorbate molecule $\mathbf{M}^{n+}$ in the bulk fluid phase diffuses (through the solvent or mixture) to the external surfaces of the solid matrices; (b) the adsorbate molecule $\mathbf{M}^{n+}$ diffuses through the internal pores of the solid matrix, reaching the "active centre" $\sigma$ on the solid material becoming attached or "fixed" on the solid material through electrostatic adsorption and (c) the adsorbate molecule $\mathrm{M}^{n+}$ and adsorption groups on the active site form a stable adsorption through chelation. To illustrate the adsorption process for a qualitative description, Fig. 12 exemplifies the steps in the adsorption process. The action of a free adsorbate molecule $\mathbf{M}^{n+}$ in the fluid phase becoming "fixed" on the solid surface is called adsorption. The kinetics of adsorption is thus controlled by both the mass transport (of the adsorbate to the active center) and the "attachment" (adsorption).

\section{Conclusions}

An amino modified cellulose adsorbent for heavy metals was pretreated using a very fast and environmentally-friendly method. The kinetic study demonstrated that the kinetic mechanism for the adsorption of metal ions followed the pseudo-second-order model, which provided the best correlation with the experimental data. The adsorption behavior of

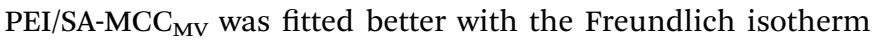
model $\left(R^{2}>0.99\right)$ with a remarkably higher adsorption capacity. The mechanism studies confirmed that the adsorption process of heavy metal ions was a chelating process.

\section{Acknowledgements}

This project was sponsored by the Guangxi Youth Natural Science Fund (GXNSFBA053025), the National High Technology Research and Development Program ("863"Program) of China (2009AA06A416), the National Natural Science Foundation of China (51108261), the Guangxi Science and Technology
Research Program (14251009), and the Natural Science Foundation of Guangxi (2013GXNSFFA019005).

\section{References}

1 L. Lü, L. Chen, W. Shao and F. Luo, J. Chem. Eng. Data, 2010, 55, 4147-4153.

2 D. W. O'Connell, C. Birkinshaw and T. F. O'Dwyer, Bioresour. Technol., 2008, 99, 6709-6724.

3 B. Qiu, C. Xu, D. Sun, H. Yi, J. Guo, X. Zhang, H. Qu, M. Guerrero, X. Wang and N. Noel, ACS Sustainable Chem. Eng., 2014, 2, 2070-2080.

4 T. Hartman, J. Sturala and R. Cibulka, Adv. Synth. Catal., 2015, 47, 3573-3586.

5 R. A. Sheldon, Catal. Today, 2015, 247, 4-13.

6 J. Ni, H. Na, Z. She, J. Wang, W. Xue and J. Zhu, Bioresour. Technol., 2014, 167, 69.

7 V. K. Tyagi and S. L. Lo, Renewable Sustainable Energy Rev., 2013, 18, 288.

8 J. Ni, N. Teng, H. Chen, J. Wang, J. Zhu and H. Na, Bioresour. Technol., 2015, 191, 229-233.

9 M. Hashem, M. A. Taleb, F. N. El-Shall and K. Haggag, Carbohydr. Polym., 2014, 103, 385-391.

10 H. Liimatainen, J. Sirviö, A. Haapala, O. Hormi and J. Niinimäki, Carbohydr. Polym., 2011, 83, 2005-2010.

11 S. Hokkanen, E. Repo, T. Suopajärvi, H. Liimatainen, J. Niinimaa and M. Sillanpää, Cellulose, 2014, 21, 1471-1487.

12 J. Su, H. Zhu, L. Wang, X. Liu, S. Nie and J. Xiong, BioResources, 2016, 11, 7416-7430.

13 L. V. A. Gurgel, R. P. d. Freitas and L. F. Gil, Carbohydr. Polym., 2008, 74, 922-929.

14 L. V. Gurgel, O. K. Junior, R. P. Gil and L. F. Gil, Bioresour. Technol., 2008, 99, 3077-3083.

15 S. Hokkanen, E. Repo and M. Sillanpä, Chem. Eng. J., 2013, 223, 40-47.

16 W. Y. Li, A. X. Jin, C. F. Liu, R. C. Sun, A. P. Zhang and J. F. Kennedy, Carbohydr. Polym., 2009, 78, 389-395.

17 Z. Du, T. Zheng, P. Wang, L. Hao and Y. Wang, Bioresour. Technol., 2016, 201, 41-49.

18 L. V. A. Gurgel and L. F. Gil, Carbohydr. Polym., 2009, 77, 142-149. 19 T. S. Anirudhan, T. A. Rauf and S. R. Rejeena, Desalination, 2012, 285, 277-284.

20 H. He, X. Hou, B. Ma, L. Zhuang, C. Li, S. He and S. Chen, Cellulose, 2016, 23, 2539-2548.

21 B. Qiu, G. Jiang, Z. Xi, D. Sun, H. Gu, W. Qiang, H. Wang, X. Wang, Z. Xin and B. L. Weeks, ACS Appl. Mater. Interfaces, 2014, 6, 19816-19824.

22 A. Roy, S. Chakraborty, S. P. Kundu, B. Adhikari and S. B. Majumder, Ind. Eng. Chem. Res., 2012, 51, 12095-12106.

23 G. Zhang, R. Qu, C. Sun, C. Ji, C. Hou, C. Wang and Y. Niu, J. Appl. Polym. Sci., 2008, 110, 2321-2327.

24 M. D. Meitei and M. N. V. Prasad, J. Environ. Chem. Eng., 2013, 1, 200-207.

25 E. Repo, J. K. Warchol, T. A. Kurniawan and M. E. T. Sillanpää, Chem. Eng. J., 2010, 161, 73-82.

26 S. Liu, J. Colloid Interface Sci., 2015, 450, 224-238.

27 S. Liu, Sep. Purif. Technol., 2015, 144, 80-89. 